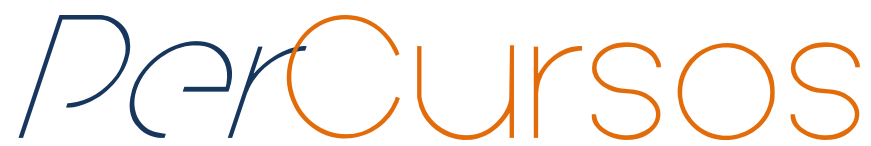

\title{
"Prefiro um filho morto do que um filho viado": algumas implicações de quando a homofobia é familiar
}

\begin{abstract}
Resumo
A situação de discriminação e preconceitos já tem sido alvo de vários estudos a fim de produzir conhecimento e tentativas de superação dessa situação. No que diz respeito ao gênero e principalmente à orientação sexual, tem sido gerado algum debate e elaboração de materiais didáticos com $\mathrm{o}$ intuito de combater o bullying homofóbico, cujas dimensões no campo da formação em educação dos sujeitos vêm sendo cada vez mais estudadas. Observando com mais cuidado o âmbito privado busco visibilizar algumas famílias em que existe divergência de orientação sexual entre pais e filhos, para pensar alguns dos desdobramentos que afetam as relações e as possibilidades de conciliá-las ou não com os valores da rede social, círculo familiar e de parentesco e suas implicações nessas histórias de vida juvenis. Por isso busquei no aparato metodológico da Antropologia e no documentário "Quenda" o tratamento dado ao tema parentesco para analisar um pouco da trajetória de três jovens.
\end{abstract}

\section{Bruno dos Santos Hammes}

Mestrando em Antropologia

Social pela Universidade Federal de Goiás - UFG

brunohammes@hotmail.com

Palavras-chave: Pertencimento. Jovem Gay. Jovem Gay.

\section{Para citar este artigo:}

HAMMES, Bruno dos Santos. "Prefiro um filho morto do que um filho viado": algumas

implicações de quando a homofobia é familiar. Revista PerCursos, Florianópolis, v. 14, n.27.

final, jul./dez. 2013. P. $178-199$.

DOI: $10.5965 / 1984724614272013178$

http: //dx.doi.org/10.5965/1984724614272013178 


\title{
"I prefer a dead son to gay son": some implications when homophobia is familiar
}

\begin{abstract}
Discrimination and prejudice has already been the subject of several studies to produce knowledge and attempts to overcome them. With regard to gender and especially sexual orientation, some debate has been generated and teaching materials have been prepared in order to combat homophobic bullying, whose dimensions in the field of formation in education of subjects are being increasingly studied. Observing the private sphere more carefully, $\mathrm{t} I$ seek to make some families visible, in which there is divergence of sexual orientation between parents and children, so we can think over some developments that affect relationships and the possibilities of reconciling them or not with the values of social network, the family circle and kinship and their implications in these life stories of young people. Therefore, I searched in the methodological apparatus of Anthropology and in the documentary "Quenda" the treatment of the theme kinship to analyze part of the trajectory of three young people.
\end{abstract}

Keywords: Belongingness. Young Gay.

Subjectivity 


\section{Introdução}

A construção do pertencimento a grupos sociais é uma das questões fundamentais, se não fundacional, das ciências sociais. Nela podemos perceber sendo levadas em conta as dimensões cultural e social da pessoa e o relacionamento desse self ${ }^{1}$ com vários grupos sociais, tanto aquele(s) do(s) qual(is) é membro, como também aquele(s) ao(s) qual(is) não pertence. Sobre estes estudos gostaria de chamar a atenção acerca da contribuição da antropologia e de seu instrumental de observação e análise, tentando demonstrar um pouco os avanços nos estudos que buscavam pensar a família. Em especial gostaria de trazer a noção de 'identidades sociais fragmentadas' (Ribeiro e Santos Júnior, 2007), na medida em que não se sustenta a ideia de um saber local totalmente homogêneo e coeso como a ideia que marcou os estudos das sociedades ditas primitivas $^{2}$, permitindo superar os binarismos simplistas e ter que,

Os sujeitos são ao mesmo tempo, homens ou mulheres, de determinada etnia, classe, sexualidade, nacionalidade, são participantes ou não de uma determinada confissão religiosa ou de um partido político. Essas múltiplas identidades não podem, no entanto, ser percebidas como se fossem "camadas" que se sobrepõem uma às outras, como se o sujeito fosse se fazendo "somando-as" ou agregando-as. Em vez disso, é preciso notar que elas se interferem mutuamente, se articulam, podem ser contraditórias, provocam, enfim, diferentes 'posições'. (LOURO, 1997, p. 51)

De acordo com o recorte escolhido, que é o de problematizar justamente uma suposta universalidade do entendimento e legitimidade de uma única forma de família, parto das reflexões de alguns autores, inclusive contemporâneos que se debruçaram sobre este tema, como o estudo de Cynthia Sarti (1992), que de maneira interessante analisou clássicos da área da etnografia de maneira tal a poder enunciar que "a contribuição da antropologia [foi] para pensar a 'desnaturalização' e a

\footnotetext{
${ }^{1}$ A noção de Self remete à consciência que o indivíduo tem da sua singularidade. Cohen (1994) parece entendê-lo como a capacidade que cada indivíduo possui para refletir sobre a experiência idiossincrática que tem de si e do mundo, mas parece tomar por garantida a forma como isso se processa (remetendo-o, sobretudo para processos de raciocínio reflexivo) e, principalmente, de que modo essa experiência é, simultaneamente, constituinte do e constituída pelo contexto social e cultural. (Urpia, 2009, p.10).

${ }^{2}$ Ver Deberet, Desafios da politização da justiça e antropologia, 2010, p.475-492.
} 
'desuniversalização' da família, desta família que nós conhecemos na nossa sociedade” (Idem, 1992, p.69).

O tema do parentesco acabou sendo o foco de boa parte dos estudos na antropologia, e Sarti (1992) nos chama atenção para uma característica das sociedades analisadas por aqueles autores que ficaram conhecidos como funcionalistas ${ }^{3}$, ou os primeiros 'contrapositores' à corrente de pensamento conhecida posteriormente como evolucionista ${ }^{4}$. Era justamente o olhar e a interpretação dados à ausência de uma estrutura social e política similar àquela experimentada pelos etnógrafos e pesquisadores em seus países/ estados-nacionais ${ }^{5}$ de origem que se tornara um dos pontos de desentendimento e visões distintas sobre as práticas e culturas das tribos visitadas.

Assim como no esforço que Sarti (1992) fez, gostaria de reiterar que as contribuições e os avanços não só da antropologia como de outras disciplinas no campo dos estudos de pertencimento foram inúmeros, tornando quase impossível revisar toda a bibliografia que já foi produzida acerca do tema. É por isso que busco concentrar esforços neste momento em um tema que emerge de maneira latente e instigante para mim, e que tem estado em voga, principalmente pelas lutas sociais por equiparação e reconhecimento, e pela complexa relação entre público e privado, que é o tema: família e parentesco.

Tomo neste estudo, como dimensão central, o rearranjo das relações familiares a partir de um evento que foge da ordem vigente neste núcleo, que é a 'revelação' de uma [homo] sexualidade, ou mais especificamente, os conflitos morais que se desdobram e decorrem desta situação, que me permitiram introduzir uma problematização de maneira a questionar um ideal de "amor incondicional", de senso comum, que considero ser imposto aos pais pela sociedade. Trabalhei para isso com alguns relatos e informações/declarações colhidas de jovens que eram o público-alvo, durante o tempo

\footnotetext{
${ }^{3}$ O funcionalismo, na antropologia, veio crescendo desde 1914, quando Malinowski iniciou seus estudos. Até então, tanto o evolucionismo como os difusionismos preocuparam-se com as origens, com os problemas das transformações socioculturais.

${ }^{4}$ Apesar da impactante influência de Charles Darwin, o evolucionismo como estudado pelos antropólogos tem uma direção um pouco distinta. Antropólogos foram mais influenciados por Spencer, e o pressuposto do evolucionismo seria o de "reduzir as diferenças culturais a estágios de um mesmo caminho evolutivo.

${ }^{5}$ Hall (1998) considera uma cultura nacional como um discurso, um modo de construir sentidos que influencia e organiza tanto nossas ações quanto a concepção que temos de nós mesmos no bojo da modernidade ilustrada e das revoluções burguesas, e impulsionado pelo industrialismo.
} 
em que estive envolvido com um projeto em uma Organização Não Governamental (ONG) do Rio de Janeiro voltado para o trabalho de promoção de cidadania entre jovens gays e bissexuais ${ }^{6}$.

Nesta época em que fui facilitador do projeto que trabalha os temas 'cidadania', 'sexualidade' e 'identidade', entre jovens gays e bissexuais, eu pude estar presente em distintos espaços, entre eles as instalações da sede da $\mathrm{ONG}^{7}$, os espaços de sociabilidade gay ou $\mathrm{GLS}^{8}$ da cidade e Região Metropolitana do Rio de Janeiro e eventos acadêmicos ${ }^{9}$. Dessa forma, pude notar muitas das questões que se entrelaçam e que envolvem 'família', ‘juventude’ e ‘sexualidade' e perceber quão recorrentes e problemáticas podem ser essas questões para esses jovens. Entre elas, o 'sair do armário ${ }^{10}$, a dependência econômica, afetiva e social desta família compõem grandes dilemas na vida destes jovens, influenciando assim suas escolhas, balizando suas subjetividades, pertencimentos, parentescos e afinidades.

Embora haja na atualidade alguma forma de visibilidade e discussão relativas às famílias homoparentais, adoção por casais lésbicos e gays, e assistência em outras questões ligadas ao campo da legalidade e reconhecimento dessas outras formas de união e família, eu percebi que havia muito pouco acúmulo e visibilidade acerca das trajetórias, dilemas e mediações que envolvem a vida de um jovem gay no seio de uma família heterossexual conservadora, mantenedora e perpetuadora de preconceitos, ideias preconceituosas e 'injúria"'. Nesse tipo de família há uma atmosfera, em geral, de suscetibilidade a todas as questões já mencionadas para os jovens gays que vivem sob a

\footnotetext{
${ }^{6}$ Projeto Entre-Garotos, dedicado a jovens gays e bissexuais. Tem financiamento holandês através da Fundação Schorer, ofereceu oficinas para 40 jovens gays e bissexuais abordando questões de saúde, sexo seguro e negociação com o parceiro para o uso de preservativo. Também falamos sobre as emoções e percepções dos jovens, buscando minimizar os danos do preconceito sofrido na escola, entre amigos, familiares e em ambientes religiosos e de trabalho. Fonte: <http://www.arcoiris.org.br/entregarotos/projeto/>.

${ }^{7}$ Durante o tempo em que estive facilitador do projeto o Grupo Arco-Íris de Cidadania LGBT estava situado à Rua do Senado, 230 - Cobertura - Centro - Rio de Janeiro.

${ }^{8}$ Acompanhando um raciocínio de nicho de mercado optou-se por utilizar a sigla GLS (Gays, Lésbicas e Simpatizantes) ao invés daquela que vem sendo usada pela militância e movimentos sociais LGBTTTs (Lésbicas, Gays, Bissexuais, Travestis, Transexuais e Transgêneros).

${ }^{9}$ I Seminário de Educação e Sexualidade do IBMR - Rio de Janeiro - 2011.

10 "Sair do armário" é uma expressão cada vez mais utilizada pelas pessoas para referir-se ao processo de "assumir-se", processo de interrogação pessoal em oposição à expectativa social, que não tem quaisquer paralelos na vida heterossexual.

${ }^{11}$ Ver Eribon (2008).
} 
autoridade de famílias heterossexuais, e que na maioria dos casos com que tive contato, ainda são intolerantes ou fóbicas à diversidade sexual.

Tratar de 'juventude' e 'sexualidade', qualquer que seja o prisma, é algo complicado. Impera nas famílias [brasileiras], nas escolas e organizações de direitos humanos, da criança e da juventude um discurso moral-religioso amparado na 'invenção da infância ${ }^{12}$ ' que não só investiu de direitos e 'preservação' no que tange à exploração do trabalho infantil, mas assegurou também a não violação dos direitos à educação e ao lazer, o que é bom. Mas ao mesmo tempo esse ideal de 'formação' baseia-se em uma perspectiva de sacralidade que entende e faz dos jovens 'seres em formação'.

Tem sido assim no entendimento e tratamento que se tem dado, por exemplo, ao tema da gravidez na adolescência, o que nos leva a perceber o papel perpetuador que esse modo tem nessa ideologia. O mesmo é de se esperar com relação à [homo]sexualidade, performance (Schechner, 2012) [social] e "transtorno" [patologizante] de gênero e transexualidade na infância. Até por que essas questões já são consideradas 'pecado' ou 'não naturais' pelo senso comum e até mesmo por parte da academia (DESSER 1993; OLIVEIRA 1998; Portaria 1376/93 do Ministério da Saúde Brasileiro ${ }^{13}$ ). Tais temas estavam e para muitas pessoas ainda estão fora da realidade. Porém a crescente organização e negociação de espaços obtidos pelos movimentos de minorias, a partir das lutas históricas dos movimentos abolicionistas e feminista, seguem ganhando força.

Para dar visibilidade a uma produção sobre a temática e por tratar justamente da discussão da revelação da sexualidade [pelos jovens] para a família e por se tratar de jovens que foram público-alvo do projeto, decidi utilizar nesse estudo o filmedocumentário “Quenda" ${ }^{14 ”}$ (2010), direção de Alexandre Bortolini e Warllem Machado. O filme não foi produzido pela Organização Não Governamental (ONG), mas traz os

\footnotetext{
${ }^{12}$ Ver ARIÉS, Philippe. História Social da Criança e da Família. Rio de Janeiro: LTC, 1981.

13 Ver Mott (2001): "Sangue Gay: Histórico da Campanha Pela Revogação da Exclusão dos Homossexuais como doadores de Sangue”. Disponível em: < http://www.ggb.org.br/sangue_gay_mott.html>.

14 “Quenda" é uma expressão muito usada pela comunidade LGBT, com origem no idioma bajubá, e significa 'chamar atenção'. Fonte: <http://www.dzai.com.br/natoviegas/blog/saindodoarmario?tv_pos_id=99368>. Acesso em: 22/02/2013 às $11 \mathrm{~h} 58 \mathrm{minh}$.
} 
depoimentos de três jovens que se enquadram no perfil e são alvos das ações e do universo com que tive contato.

Todos eles são maiores de 18 anos e estão contando suas próprias histórias ${ }^{15}$. 0 filme tem como cenários três festas do Rio de Janeiro, desde Copacabana [área nobre] até a noite de Madureira [no subúrbio], passando pela Parada do Orgulho LGBT do Município de Niterói [região metropolitana], onde os três meninos, Giul ${ }^{16}$, Caio ${ }^{17}$ e Daniel $^{18}$, cada um à sua maneira, mostram suas festas preferidas, contam como a família descobriu sobre sua sexualidade, como é a vida entre os amigos e nas suas comunidades/vizinhança.

\section{Parentesco e seu universo: uma breve revisão}

Introduzo aqui a discussão a partir do ponto de vista de Friedrich Engels (1984) sobre família, que consiste em um "círculo compreendido na união conjugal comum, e que era muito amplo em sua origem, se estreita pouco a pouco até que, por fim, abrange exclusivamente o casal isolado, que predomina hoje". (Idem, p. 31). Assim, essa noção de família resultante desse processo histórico chamada de monogâmica imprimia nessa restrição ou isolamento conjugal uma força, coesão, a fim de estabelecer e fortalecer laços capazes de garantir e permitir uma sociedade cada vez mais baseada na economia, acúmulo e troca. Não era concebida, durante muito tempo, a possibilidade concreta de se desfazer tais laços, com exceção de alguns casos previstos que, via de regra, privilegia[va] o homem e sua titularidade sobre os bens [entre eles os filhos], pois tinham relação com sua honra pessoal e com a conduta social, moral e sexual da esposa. Como exemplo, é de largo conhecimento a previsão de divórcio caso o noivo/esposo duvidasse ou constatasse que a noiva já não era mais virgem, demonstrando um entendimento machista e de posse sobre a companheira.

\footnotetext{
${ }^{15}$ Todos os nomes são verdadeiros bem como as histórias e identidades.

${ }^{16}$ Giulson Jr, 19 anos, estudante universitário e militante pelos direitos aos LGBT na ONG Grupo Diversidade Niterói (GDN).

${ }^{17}$ Caio Almeida, 21 anos, estudante, morador de Madureira, zona norte do Rio de Janeiro.

${ }^{18}$ Daniel Alves, 21 anos, estudante universitário, morador de Botafogo, zona sul do Rio de Janeiro.
} 
Dessa maneira, a leitura de Manuel de Castells (1999) feita por Débora Regina Barbosa (2008) concentra sua atenção e análise "na família e no patriarcalismo e em como estes permeiam, organizam e dominam a cultura e os comportamentos nas sociedades ocidentais" (CASTELLS apud. BARBOSA, 2008, p.10). Retiro do próprio Castells (1999, p. 173), que discorre sobre a "crise da família patriarcal, o enfraquecimento do modelo familiar baseado na autoridade/dominação contínua exercida pelo homem, como cabeça do casal, sobre toda família". Usando como base as estatísticas cujo refinamento está justamente em entender que se trata de estrutura populacional tão fortemente presente e internalizada, portanto mudanças que "costumam evoluir em ritmo muito lento" (Idem, 1999, p. 173), aponta a "existência de tendências afetando a estrutura e a dinâmica da família patriarcal observadas em estatísticas" (Idem, loc. cit).

Mas e os filhos? Ainda nesta perspectiva nuclear e patriarcal, os filhos passam também a ser uma das posses [prolongamento e perpetuação], são os herdeiros do casal e de todo seu legado [principalmente quando este é de sucesso]. Percepção está bem diferente de outras realidades, como as que Morgan (em 1877) narrava ter tido contato, inclusive no que aconteceu com ele. Em tendo ficado tanto tempo com os iroqueses, acabou sendo "adotado" por uma de suas tribos, a dos senekas. Retomando Morgan, Engels (1984, p. 28) aponta que "o iroquês não somente chama filhos e filhas aos seus próprios, mas, ainda, aos de seus irmãos, os quais, por sua vez, o chamam de pai. Os filhos de suas irmãs, pelo contrário, ele os trata como sobrinhos e sobrinhas", demonstrando assim como se processa no interior de cada sociedade a lógica do(s) parentesco(s).

\section{Parentesco e heteronormatividade: revisões recentes}

Postas algumas das contribuições interessantes destes autores que ajudaram a pensar o parentesco, e aqui já avançando para o período mais recente, torna-se uma ferramenta analítica muito importante para essa interpretação o conceito de relatedness apresentado por Carsten (2004), que implica modos de se relacionar que se constituem a 
partir de vários elementos - substância, alimentação, convivência, afeto, procriação -, podendo se combinar de várias formas e ganhar conteúdos específicos para grupos sociais particulares. É assim uma categoria mais fluida e mutável de parentesco, que não desconsidera a importância de substâncias como o sangue, mas que entende que há no convívio e nas afinidades entre os indivíduos elementos importantes que deveriam ser considerados pelos teóricos para a conceituação e para os estudos das relações entre as pessoas.

Entre estas relações poderíamos tratar não só do parentesco, mas das amizades, das relações de convívio no trabalho e de outros que impõem ou o convívio ou estão condicionadas a sua ocorrência de maneira compulsória [sem possibilidade de "optar" ou não por ele]. Para trazer um pouco dos fatos e discussões atuais acerca destas possibilidades de interações, bem como para exemplificá-las, preferi enfocar neste trabalho um tipo específico de relações de família que tem de especial o fato de serem conflituosas. Nessa sessão farei uma breve consideração analítica delas para mostrar um pouco do porque considero que esta situação se torna relevante: por expressar e revelar um contrassenso que é justamente uma relativização do suposto 'amor incondicional'.

Essa situação se apresenta um tanto paradoxal em relação a um discurso e a uma ideia que se tem disseminado na sociedade. O que acontece é que onde, em teoria, haveria o amor e a doação total, expressos através de zelo, compreensão, cuidado e afeto, ao se constatar ou ao se revelar um fato, nesse caso uma condição sexual diferente da 'normal' (a esperada heterossexualidade), surgem alguns conflitos.

Além de perturbar ou mexer com a imposição que envolve e define o "amor filial”, a situação em si acaba por ser conflitante com os costumes, com os valores ou práticas arraigadas naquele núcleo familiar ou social, o que pode acabar gerando a desestabilização das relações, tornando latente o sentimento de frustações de expectativas, insubordinação a 'quem te cria e provê seu sustento', bem como outras inúmeras reações tão imprevisíveis e inesperadas que acabam, porém, sendo justificadas frente a esse ideal e a um imaginário de "rebeldia" juvenil. Segundo Schulman (2009, p. 70), “Devido à natureza invertida do comportamento dominante, as pessoas gays estão 
sendo punidas no interior da estrutura familiar, mesmo que nunca tenham feito nada de errado." 19

Conjugam-se nesta situação algumas questões, como já foi dito. Primeiro uma frustração dos pais em relação às expectativas sociais; em segundo a possibilidade da escolha do filho de ser publicizada ou tornada de conhecimento da vizinhança, o que levaria a comentários, fofocas e perda de algum tipo de prestígio ou reconhecimento social. Esse fato em si, por se opor à norma e aos valores familiares é encarado como algum grau de insubordinação, precisando então ser punido e corrigido. "Ainda hoje as famílias estão mais propensas a "tolerar" os homossexuais, isto é, a mantê-los em uma posição de menor valor do que aprender com eles e se inspirar em seu conhecimento". (SCHULMAN 2009, trad. Martins Fernandes, 2010, p. 70).

Não são raros e conhecidos as narrativas e conhecimento de declarações emitidas pelos parentes, recorrentemente pelas mães, afirmando "eu preferiria um filho morto do que viado" ou até mesmo como narrou um jovem,

Na quinta série já com onze anos, eu falei pra minha mãe, em casa. Só 'tava' eu e ela em casa. Ela teve um ataque, ficou transtornada, não parava de chorar, não dormiu a noite inteira. Falou que 'preferia que eu fosse drogado', falou um monte de besteira. (Daniel Alves, 21 anos, estudante, grifo meu)

Essas afirmações, embora se perceba que em alguns casos estão embebidas de emoção e falta de habilidade para tratar da situação, muitas vezes são convicções que perduram, interferem e interrompem o diálogo e a relação da família com o filho ou com o "parente gay", isolando ou excluindo assim esse filho, esse jovem. Tal fato "pode se tornar uma opressão dolorosa determinante na vida da pessoa gay. Pior do que isso pode ser o modelo através do qual as pessoas gays tratem umas as outras" (SCHULMAN 2009, trad. Martins Fernandes, 2010, p. 69).

Embora haja inúmeras justificativas que tornem lógico um pensamento de senso comum que naturaliza ou replica essas opressões sob a forma de "tratamento" ou

\footnotetext{
${ }^{19}$ SCHULMAN, trad. Martins Fernandes 2010, p.70.
} 
isolamento, essa situação, como já afirmado antes, é uma das possibilidades de vivenciar ou construir relações de parentesco [biológico/social]. A partir dessa e de outras expressões da realidade que são exponencialmente divulgadas é que podemos pensar em trabalhar com a noção de "relacionalidade" ou relatedness para refletir acerca das visões de senso comum que estão arraigadas em nossa sociedade, empoderando e visibilizando assim essas questões atuais que podem, com esse arcabouço teórico, ser mais bem trabalhadas.

Uma forma possível de pensar as relações genealógicas enquanto formas primárias de estabelecer conexão, um primeiro contato. Porém, isto não é suficiente, pois há um espaço que precisa ser preenchido por signos de proximidade. (LOBO, 2006, p. 15)

Trago uma leitura recente de Judith Butler (2003) que trata das expectativas e pressupostos que legitimam e reiteram uma forma de união: o casamento e o parentesco heterossexual. Ainda vamos ver nesse estudo de Butler (2003) outras dimensões que podem estar em jogo condicionando ou dando contorno às questões de parentesco. Podem estar atuando interesses, como o das nações, econômicos, religiosos e até mesmo raciais ou étnicos, esse último visto no trecho acima. Quanto aos interesses econômicos, esses têm um sentido mais amplo que envolve, como aludido antes, uma dimensão afetiva, uma espécie de "economia do afeto" e uma expectativa da norma social, além do entendimento estritamente monetário e de posse de coisas valoráveis. Portanto, "não é possível separar as questões de parentesco das relações de propriedade (concebendo pessoas como propriedade) e das ficções de 'laços sanguíneos', assim como dos interesses nacionais e raciais que sustentam esses laços ${ }^{20 "}$.

Muitas são as críticas e as justificativas para que haja tanto esforço em normatizar e normalizar o parentesco, seja por justificativas teológicas, filosóficas ou até mesmo legais. Desse esforço, ficam algumas impressões, das quais a primeira é a de retomar as críticas de Engels (1984) ao perceber alguma funcionalidade da família mononuclear patriarcal para um propósito econômico, o que de alguma maneira nos traz a impressão

\footnotetext{
${ }^{20}$ BUTLER. Cadernos Pagu, v. 21, p. 219-260. 2003.
} 
de uma estreita relação com o ideal reprodutivo desse tipo de família e, principalmente, de sua heterossexualidade compulsória, que diz respeito aos padrões vigentes de comportamento e de expectativas. Assim,

\begin{abstract}
Variações no parentesco que se afastem de formas diádicas de família heterossexual garantidas pelo juramento do casamento, além de serem consideradas perigosas para as crianças, colocam em risco as leis consideradas naturais e culturais. (BUTLER, 2003, p. 224)
\end{abstract}

Utilizei textos recentes para definir dois termos que tratam de homossexualidade e família, mas que têm um refinamento teórico na questão de quem é o sujeito interlocutor, que requer ou é posto sobre a situação familiar. Dessa maneira, vou trabalhar com o par teórico: homoparentalidade a partir de Fonseca (2008) e 'Homofobia Familiar' a partir de Schulman (2009). Para esse estudo utilizarei o segundo conceito, por entender que não se trata de uma situação onde há casais homoparentais em conflito com seus filhos, e sim conflitos e dilemas relativos à [homo]sexualidade do filho.

Logo temos que a "homoparentalidade" nos obriga a repensar as categorias básicas de nosso parentesco. Ao afastar a discussão da "tradicional família nuclear", isto é, da procriação sexuada e da filiação biogenética" (Fonseca, 2008, p. 769), já estamos pensando em "homofobia familiar" que, para os jovens gays, "é uma experiência comum em que fomos, cada um de nós, em algum momento de nossas vidas, inferiorizados por nossas famílias simplesmente por causa de nossa homossexualidade" (SCHULMAN, 2010, p. 69).

A desnaturalização e visibilização dessa realidade podem gerar conhecimento, e como a própria Schulman (2009) diz, "articular como e por que os sistemas de homofobia familiar operam e, mais importante, como podem ser transformados" (Idem, p.69). Neste sentido, tomo a revelação da sexualidade na juventude como um momento em que se inicia a transformação de uma determinada rede de parentesco, pondo em foco a construção, reorganização ou rompimento de vínculos. Apesar de sua relevância na constituição do indivíduo e dos dilemas pessoais, a diferente orientação sexual do jovem na família tem sido objeto de poucos estudos nas ciências sociais, em contraste com a 
vasta literatura (Fonseca 2008; Grossi 2003) sobre família e suas transformações recentes, incluindo as discussões de adoção e casamento homossexual.

As possibilidades reais de pesquisa com jovens homossexuais [ou não] até tempos recentes e até mesmo hoje são muito delicadas, haja vista a "criação de imagens e preconceitos sobre a juventude contemporânea, principalmente pelas mídias, que interferem na nossa maneira de compreender os jovens. A juventude é vista na sua condição de transitoriedade, onde o jovem é um 'vir a ser”' (DAYRELL, p. 40-41, 2003).

Partindo dos estudos de Didier Eribon (2008) em "Reflexões sobre a Questão Gay", gostaria de trazer aqui algumas das conclusões que seu trabalho me permitiu fazer acerca das relações no espaço urbano. Para o autor a cidade apresenta-se como um arranjo social que possibilita "um mundo de socialização possível, e ela [a cidade] permite superar a solidão tanto quanto protege o anonimato" (ERIBON, 2008, p.35) e a vivência da homossexualidade.

Essa foi uma premissa que me permitiu tomar contato com as questões do universo gay, e através da experiência de atuação no movimento social, buscar refletir sobre a ideia de que o anonimato e liberdade na cidade grande, bem como a "fuga para a cidade", como os espaços de sociabilidade [ditos] discretos e específicos, o medo provocado pela 'injúria', as performances corporais e de gênero, o anonimato ou a “dissimulação" se tornam importantes para a [sobre]vivência desses jovens dada à hostilidade e fobia com a qual se imagina e espera ser tratado pela sociedade e círculo social próximo cotidianamente.

Assim, apesar das devidas diferenças, algumas características das narrativas que enunciam uma trajetória mais ou menos comum aos jovens gays norte-americanos também podem ser observadas entre os jovens brasileiros que, para título de estudo, estão circunscritos à região metropolitana do Rio de Janeiro, e que foram importantes para que eu pudesse perceber e acompanhar os relatos formais e informais colhidos junto a jovens gays, mais especificamente, os depoimentos e os trechos que serão analisados e que serviram de base para esse estudo.

Tentando identificar as proximidades e aplicação dos estudos de Eribon (2008) com o que eu estava ouvindo e colhendo dos jovens atendidos pelo projeto da ONG, me 
deparei com situações semelhantes ou idênticas às narradas pelo autor em seu livro, as quais se repetiam nas histórias de vidas destes jovens. Uma das situações que se expressava de forma branda implicava em um "mal-estar" geral na família; os pais podiam ainda, se pensarmos em uma escala de intensidade, passar a 'discussões', e em seguida, num patamar mais grave, passar a brigas, chegando ao extremo de ocorrerem agressões físicas e verbais.

Meu pai ficou meio atordoado e até hoje ele não sabe conversar comigo por causa disso. Eu e meu pai a gente não conversa muito, ainda mais sobre sexualidade. Sobre sexualidade a gente não conversa mesmo. Durante algum tempo eles não aceitaram, me prenderam em casa. (Giul, 19 anos, estudante)

Mas tão traumático ou mais que esses são os casos em que se verbaliza um rompimento, momentâneo que seja, de relações e a negação das mesmas, sempre associada à 'vergonha' do pertencimento àquele núcleo familiar e à ‘anulação' social do vínculo de parentesco.

Brigas e abandono da família colocam as pessoas em situação de vulnerabilidade e são traumáticos quando se trata, por exemplo, de duas pessoas adultas e independentes financeiramente, como é o caso de quando um casal que se separa. Há de se perceber então um agravante quando o abandono ou a briga ocorre entre um adulto [pais] e um jovem. Principalmente um menor de idade, que geralmente não possui nem independência financeira nem meio de se manter. Ao abandonar o jovem à própria sorte, colocando-o pra fora de casa, os familiares ou os parentes que cometem esta ação estão restringindo as possibilidades e dificultando um leque maior de chances e escolhas pessoais que aquele jovem teria a sua disposição estando no seio da família.

Falando de juventude e sexualidade, gostaria de explorar um pouco aqui a relação entre juventude, homossexualidade, silêncios e "armários", enfocando jovens que na maioria das vezes não são independentes financeira e, [possivelmente] emocionalmente, ou que ao optarem por revelar seu segredo podem perder seja economicamente, seja em termos de convivência, 
Elas [mãe e irmã] perderam acesso a essa parte da minha vida. Pode até ficar repetitivo, mas eu acho que a coisa que mais me marcou foi minha mãe. Eu juro pra você que eu não esperava essa reação dela. Esperava outra coisa. Nós éramos muito amigos, eu gostava muito dela, muito dela. (Daniel Alves, 21 anos, grifo meu)

Este relato deste jovem deixa muito claro que é talvez nesse momento que fica evidente que o amor não é incondicional e que de alguma maneira eles terão de aprender a lidar com isso, o que significa pactos e contratos de convivência para esses jovens,

Você sempre pensa o pior. Eu tomei um susto, ela foi 'super' receptiva, foi tranquilo. Ela disse, 'não meu filho. Eu já sabia. Já sentia, mãe sente'. Só que ela falou assim, 'Eu só não quero ver de novo! Eu não quero que isso aconteça aqui dentro de casa! (Caio Almeida, 21 anos, grifo meu)

Gostaria aqui de dizer que esse não é um padrão único de vida ao qual está fadado um jovem gay, bissexual e etc. Há chances de ela/e conseguir passar por essa fase crítica da convivência e conseguir se manter no seio da família e há ainda famílias, mesmo que uma minoria, que aceitam a revelação do filho. Visto que é essa família que lhe acolhe, nem que para isso ele tenha que agir, seja dissimulando, 'performando' ou até mesmo se 'camuflando' a fim de não chamar atenção pra si e não ser notado. Gostaria de lembrar que os depoimentos de jovens que aqui estão sendo analisados preconizam núcleos familiares onde há resistência, velada ou não, a sexualidades não normativas.

Assim, dois dos três jovens que estão no vídeo, falaram sobre como passaram pelo episódio da revelação ou “descobrimento" da sua sexualidade pelos parentes:

Na quinta série, já com onze anos, eu falei pra minha mãe, em casa. Só 'tava' eu e ela em casa. Ela teve um ataque, ficou transtornada, não parava de chorar, não dormiu a noite inteira. Desde então ela [mãe] não toca mais no assunto. Fingi que eu não falei sobre isso. Fingi mesmo. Sabe? 'Tipo', tenta me empurrar namorada e tudo. (Daniel, 21 anos, universitário, grifo meu) 
Podemos assim entender essa expressão como uma dissimulação do gênero ou uma performance (Goffman, 1996; Schechner, 2012) dissimulada de si. Há uma intenção em passar para aquelas pessoas do círculo familiar e social mais próximo uma ideia que não condiz com uma "vontade", "escolha" ou "orientação sexual”: "Com o tempo você vai vendo que você não pode fazer certas coisas em certos ambientes" (Daniel, 21 anos, universitário). Ainda sobre essas performances (Butler,1988; Goffman, 1996; Schechner, 2012), outro jovem afirmou,

$\mathrm{Eu}$, eu tenho trejeitos mais afeminados e isso foi se desenvolvendo com o tempo. Eu não falei pra minha família, eu cheguei a ter namorada de fachada. Amiga 'sapatão' que vai pra casa pra fingir que é namorada, que é 'supernormal'. (Giul, 19 anos, solteiro e se identifica como gay, grifo meu)

Se há total falta de vontade ou não nessas experiências não é possível concluir, pois não há elementos nem vontade de rotular as experiências sexuais dos indivíduos. Mas é perceptível, pela narrativa, que os jovens tem se valido de ou 'criado' situações de exposição excessiva desse seu comportamento afetivo ou sexual com a finalidade de afirmar ou endossar uma sexualidade.

Essas primeiras narrativas foram estudadas com menor detalhamento justamente por não terem tão nítido nas falas os episódios sobre os quais esse ensaio se debruça, que são aquelas histórias de vida que configuram o que Eribon (2008) chama de 'fuga para a cidade'. A distância geográfica, a fuga para as (grandes) cidades, atenua ou resolve os problemas e as questões entre sexualidade e família, seja de maneira 'pactuada', sob algum pretexto que justifique a mudança, seja de forma menos amistosa e com a finalidade de marcar o rompimento do controle ou até mesmo para tentar 'uma nova vida'.

Esse perfil, que tem como elo a procura ou necessidade de distância espacial da família de origem, chama atenção por justamente, como poderá ser observado, narrar histórias de busca e construção de novas relações sociais, relações essas que por inúmeros motivos, seja carência ou até mesmo sobrevivência, ganham muita importância 
para esse jovem. E a partir daí essa relação pode substituir a familiar ou ocupar um “lugar" na vida desse jovem.

Essas novas amizades passam a nortear e apurar as escolhas dos indivíduos. A própria aproximação da qual resulta a relação, ou o contato por si só, como já disse anteriormente, é uma escolha. Se analisarmos bem, por menos que pareça haver possibilidade de escolha, esta existe. Afinal, como já salientei, há mecanismos paliativos ou atenuadores destas tensões e atritos. Uma vez feita essa escolha, a mesma implica em uma espécie de "recomeço", que por um lado pode ser bom, mas que por outro tem seus ônus.

Pode ser interessante para o sujeito que se vê, ou tem a sensação de estar, livre de perseguições, das tensões e até mesmo de algumas pessoas. Porém esse mesmo anonimato e desconhecimento pode se tornar um empecilho, uma vez que o jovem está em um lugar diferente, com hábitos e pessoas diferentes que não terão tanta boa vontade com ele como tinham as redes anteriores. Talvez houvesse mais solidariedade [mínima] decorrente do parentesco e da fixação da família no bairro ou cidade. Aquela mesma família com a qual vivia em tensão, tinha lhe dado um capital que era muito útil para se situar e relacionar em seu local de origem.

O que pode não se aplicar a outra cidade, ainda mais no caso de uma cidade grande, marcada pela impessoalidade e superficialidade George Simmel (1967). Pode não haver nesse outro lugar quem o ensine, nem a quem esse jovem recorrer a princípio em uma situação de necessidade. Por isso, talvez, que se diga que as grandes metrópoles são lugares tão impessoais. Mas os jovens que passaram por essa situação revelaram que a partir da conquista de um emprego, ou através de cursos ou faculdade, e ao se deparar e ter que estar com um número grande de pessoas de origens e contextos diferentes, se abria então uma possibilidade de entrar em contato com pessoas parecidas com eles.

Tão reconfortante quanto à possibilidade de ter alguém por perto que está passando pela mesma situação é a possibilidade de conhecer alguém que tenha o conhecimento de outras pessoas e de ser inserido por intermédio desta pessoa em um ciclo afim. Não se advoga pela formação de guetos, visto que é quase impossível que as pessoas se fechem em círculos ou grupos totalmente isolados do mundo das relações 
interpessoais. Mas também deve se considerar a importância e o papel que essas pessoas passam a ter para estes jovens: "eles são a família que eu nunca tive", dizem os dois jovens ao se referirem a esses amigos que se fazem tão presentes na vida e nas situações cotidianas.

Por estarem tão presentes na vida uns dos outros, essas relações que a princípio são encaradas como amizades são carregadas de mais emoção e passam a ser encaradas com mais seriedade: "nossa amizade é coisa séria [...] confio nos meus amigos", diz um dos jovens quando o questionei sobre a lealdade dos amigos-irmãos. Às vezes há tanta expectativa e confiança depositada que, como afirma Weston (1995, p.91), "a noção de amizade vira de cabeça para baixo a associação cultural que apresenta a conexão biogenética como a que permanece, pois, aqui, a amizade é a relação mais segura e duradoura".

As noções de "dar segurança" e "relação duradoura" que a autora nos traz são condições importantes para a manutenção tanto das amizades quanto do estabelecimento dessa nova vida. [Sentir] segurança é uma condição básica para a plena liberdade e expressão, seja ela num entendimento psicológico, político ou social.

Quando a gente passava e eles diziam 'passa borboleta' a gente manda praquele lugar'. A gente passou a chamar os 'caras homofóbicos de gostosos', ficar zuando eles. Foi uma forma de mostrar pra eles que, tipo, não é só eles que podem zoar a gente, a gente também tem motivos para zoar eles. (Giul, 19 anos, estudante, grifo meu)

Dar segurança é um papel esperado da família, seja na noção de 'aconchego' e 'proteção', seja na noção de 'amor' ao longo da vida, potencializada pelo incentivo às aptidões pessoais. A família deveria ser uma espécie de rede de solidariedade onde o jovem acharia apoio e receberia estímulos para fortalecimento e meio de acesso ao pleno campo de possibilidades na vida, dada a importância investida nos laços sociais. Porém, a família e suas normas pré-estabelecidas podem se revelar mecanismos de coerção do indivíduo a se adequar à norma social e/ou familiar.

A realidade tem se mostrado um pouco mais perversa do que a teoria e não tem aliviado a mão. Não é de hoje que sabemos ou ouvimos falar de vizinhos e conhecidos 
que cochicham ou constrangem publicamente gays taxando-os como "marica" "bicha", ou até mesmo "pervertido" e "mulherzinha”. O último talvez tenha uma importância e um destaque por revelar comparações e proximidades em relação ao universo e papéis sociais desenvolvidos por homens, mulheres, crianças e idosos. Cabe aqui um parêntese que nos faz pensar e entender um pouco do universo machista que ao mesmo tempo se revela tão misógino ao projetar e reduzir as expressões do feminino a estereótipos e funcionalidades sexuais.

Mas voltando à realidade [um tanto perversa] que nos traz narrativas e elementos que distanciam tanto esses "viadinhos" dos seres sacralizados e em processo de formação com os quais a teoria identifica os jovens, há de se pontuar que não se está tentando estabelecer uma oposição entre "processo formador" e "realidade" aqui. Apenas estamos tentando trazer elementos concretos que permita relativizar um ideal purista que mostra os jovens como seres passivos em sua própria formação.

É exatamente este o ponto deste trabalho: demonstrar que estes jovens, sujeitos da/e pesquisa, que comportam uma série de especificidades, são podados de uma série de possibilidades/ maneiras ao lidarem com a situação concreta desfavorável que é o conflito. Esse conflito é agravado pelo fato de a existência e vida deste jovem muitas vezes depender das relações sociais com os/as parentes, as quais são influenciadas por uma realidade social de vizinhança e escola que, por sua vez, também influenciam, como todo ator social, a realidade em que estão inseridos, confirmando assim uma ideia de que não há total passividade no processo de formação, por mais que se percebam fortes coerções sociais no objetivo de condicionar os indivíduos.

Em termos teóricos mais amplos, trata-se de uma discussão que envolve uma questão fundamental às ciências sociais: a relação entre indivíduo e sociedade. As indagações acima permitem não apenas compreender as dinâmicas de construção de pertencimento familiar, mas também ideias a respeito de como se forma o indivíduo e a subjetividade.

Por fim, esse trabalho cumpre uma tentativa de - a partir do método de pesquisa da Antropologia, o método etnográfico - conseguir visibilizar algumas experiências de sujeitos a fim de embasar uma discussão, a qual nem sempre pode ser detectada em 
análises macrossociais, com o objetivo de alargar e trazer outros elementos das subjetividades ao processo de ensino/aprendizagem. Algo que pode revelar elementos e políticas públicas que interferem no espaço escolar visando garantir uma Diversidade neste espaço, afirmando sujeitos e trajetórias interseccionados por diversos marcadores como classe, gênero, raça, religião e suas implicações.

\section{Referências Bibliográficas}

BARBOSA, Débora Regina. Império do Amor Romântico: diferenças culturais e sexuais em casais de noivos no Brasil e na Itália. 2008. 122p.Tese (Doutorado em Psicologia) Universidade de São Paulo, São Paulo.

BORTOLINI, Alexandre. Diversidade Sexual na escola. Rio de Janeiro: UFRJ, 2008.

BUTLER, Judith. Is Kinship Always Already Heterosexual? Differences: A Journal of Feminist Cultural Studies. Tradução: Valter Arcanjo da Ponte. Cadernos Pagu, v. 21, p. 219260, 2003.

CARSTEN, Janet. "Introduction". In: CARSTEN, J. (Ed.). Cultures of relatedness. New approaches to the study of kinship. Edinburgh: Cambridge University Press. 2000.

CASTELLS, Manuel de. A Sociedade em Rede. A Era da Informação: Economia, Sociedade e Cultura, São Paulo: Paz e Terra. 1999. v. I.

COHEN, Cathy J. 'Punks, bulldaggers, and welfare queen: The radical potential of queer politics?' In: Johnson, E. P.; MAE, G. H. (Ed.). Black Queer Studies. Duke: Duke University Press, 2005.

DAYRELL, Juarez. O jovem como sujeito social. Rev. Bras. Educ., n.24, p. 40- 52. 2003.

DEBERET, Guita Grin. Desafios da politização da justiça e antropologia. Revista de Antropologia da USP, São Paulo, SP, v.53, n. 2, p. 475-492, Jul./dez., 2010.

DESSER, Nanete Ávila. Adolescência, sexualidade e culpa. Rio de Janeiro: Rosa dos Tempos; Brasília, DF: Fundação Universidade de Brasília, p.17-39, 1993.

ENGELS, Friedrich. A Origem da família, da propriedade privada e do estado: trabalho relacionado com as investigações de L. H. Morgan. 9.ed. Trad. Leandro Konder. Rio de Janeiro: Civilização Brasileira, 1984. 
ERIBON, Didier. Reflexões sobre a questão gay. Trad.: Procópio Abreu. Rio de Janeiro: Companhia de Freud, 2008.

FONSECA, Cláudia. Homoparentalidade: novas luzes sobre o parentesco. Rev. Estud. Fem. v.16, n.3, p. 769-783. 2008.

GOFFMAN, Erving. A Representação do eu na vida cotidiana. Petrópolis (RJ): Editora Vozes, 1996.

GROSSI. Miriam Pillar. "Gênero e parentesco: famílias gays e lésbicas no Brasil”. Cadernos Pagu, v. 21, p. 261-280. 2003.

HALL, Stuart. A identidade cultural na pós-modernidade. Rio de Janeiro: DP\&A, 1998.

LOURO, Guacira Lopes. Gênero, sexualidade e educação: uma perspectiva pósestruturalista. Petrópolis (RJ): Vozes, 1997.

MALINOWSKI, Bronislaw. A Vida Sexual dos Selvagens. Francisco Alves: Rio de Janeiro, 1983.

OLIVEIRA, Maria Waldenez de. Gravidez na adolescência: Dimensões do problema. Cad. CEDES vol. 19 n. 45, p.5, Campinas Julho 1998.

RIBEIRO. Luiz Cesar de Queiroz.; SANTOS JÚNIOR, Orlando Alves dos. Democracia e segregação urbana. Reflexões sobre a relação entre cidade e cidadania na sociedade brasileira. Revista Eure, 29(88), 79-95, 2003.

SARTI, Cynthia Andersen. Contribuições da Antropologia para o Estudo da Família. Psicologia USP, São Paulo, v.3, n. 1/ 2, p. 69 - 76,1992.

SCHECHNER, Richard. Performance e Antropologia de Richard Schechner. Rio de Janeiro: Ed. Mauad X, 2012.

SCHULMAN, Sarah. Familial homophobia: an experience in search of recognition. In: - Ties that Bind: Familial Homophobia and Its Consequences. New York: New Press, 2009. Tradução: Felipe Bruno Martins Fernandes. Revista Bagoas, n. 05, p. 67-78. 2010.

SIMMEL, Georg. A metrópole e a vida mental. In: VELHO, Otávio Guilherme (Org.). O fenômeno urbano. Rio de Janeiro: Zahar Editores, 1967. 
URPIA, Ana Maria De Oliveira. TORNAR-SE MÃE NO CONTEXTO ACADÊMICO: narrativas de um self participante. 2009. xxx f. Dissertação (Mestrado em Psicologia) - Universidade Federal da Bahia, Salvador.

WESTON, Kath. Families We Choose: Lesbians, Gays, Kinship. New York: Columbia University Press, 1992. 